\title{
Transitional Era: from analogical to digital workflow in oral rehabilitation: a case report
}

\author{
Era de transição: do fluxo de trabalho analógico para \\ o digital em reabilitação oral: relato de caso
}

\author{
Adrielly ZAVOLSKI ${ }^{1}$ iD https://orcid.org/0000-0003-3281-0000 \\ Francielly GRANVILLE ${ }^{1}$ iD https://orcid.org/0000-0002-9483-0368 \\ Marcos Cezar POMINI2 iD https://orcid.org/0000-0001-8129-7165 \\ Fabio Brasil de OLIVEIRA ${ }^{1}$ iD https://orcid.org/0000-0002-9207-8694 \\ Lidia Olga Bach PINHEIRO1 iD https://orcid.org/0000-0003-4775-4961 \\ Patricio RUNNACLES ${ }^{1}$ iD https://orcid.org/0000-0003-3514-7013 \\ Adriana Postiglione Buhrer SAMRA' iD https://orcid.org/0000-0001-7103-1099
}

\begin{abstract}
Digital dentistry is a ubiquitous phenomenon nowadays but it requires access to technologies and learning curve. To aid digital workflow implementation, digital steps can be progressively incorporated in conventional workflows. We aimed to demonstrate a multidisciplinary oral rehabilitation performed mixing conventional procedures with digital open-source software programs and low-cost devices. A 46-year-old female patient had photographs, intraoral scans, and cone-beam computed tomography obtained and used in combination with conventional clinical exams to develop a treatment plan. Power point software was used for digital smile planing and Horos for digital implant planning. The digital dataset were used to guide conventional clinical procedures (scaling and root planning, gingivoplasty, in-office tooth bleaching, fiber-post restoration, implant and bone graft placement, teeth preparation, and protheses design and milling). The inclusion of digital steps in the conventional workflow enabled the performance of rehabilitation procedures with reduced clinical time and increased predictability, favoring the overall workflow and the communication among the different dental specialties. A mixed workflow can progressively lead to an exclusively digital workflow as technologies become accessible and learning curve is coped.
\end{abstract}

Indexing term: Computer-aided design. Prosthodontics. Technology, dental. Workflow.

\section{RESUMO}

Atualmente, a Odontologia digital é um fenômeno onipresente, contudo exige acesso à tecnologia e curva de aprendizado. Para auxiliar na implementação de fluxos de trabalho digitais, etapas digitais podem ser progressivamente incorporadas nos fluxos de

\footnotetext{
1 Universidade Estadual de Ponta Grossa, Departamento de Odontologia. Ponta Grossa, PR, Brasil.

2 Universidade Estadual de Campinas, Faculdade de Odontologia de Piracicaba, Departamento de Prótese e Periondontia. Av. Limeira, 901, Areião, 13414-903. Piracicaba, SP, Brasil. Correspondence to: MC POMINI. E-mail: <marcospomini@outlook.com>.

$\boldsymbol{v} \boldsymbol{\nabla v}$

How to cite this article

Zavolski A, Granville F, Pomini MC, Oliveira FB, Pinheiro LOB, Runnacles P, et al. Transitional Era: from analogical to digital workflow in oral rehabilitation: A case report. RGO, Rev Gaúch Odontol. 2021;69:e20210032. http://dx.doi.org/10.1590/1981-86372021003220200045
} 
trabalho convencionais. Nosso objetivo foi demonstrar uma reabilitação oral multidisciplinar realizada combinando procedimentos convencionais e ferramentas digitais de baixo custo e acesso aberto. Uma paciente de 46 anos teve fotografias, exames intraorais e tomografia computadorizada de feixe cônico obtidos e usados em combinação com exame clínico convencional para desenvolvimento de um plano de tratamento. O software Power Point foi utilizado para o planejamento digital do sorriso e o Horos para o planejamento digital dos implantes. O conjunto de dados digitais foi usado para orientar a execução dos procedimentos clínicos convencionais (raspagem e alisamento radicular, gengivoplastia, clareamento dental, restauração com pino de fibra de vidro, inserção de implantes e enxerto ósseo, preparos protéticos e design e fresagem protética). A inclusão de etapas digitais no fluxo de trabalho convencional permitiu redução do tempo clínico na realização da reabilitação aliado à maior previsibilidade, favorecendo o fluxo de trabalho e a comunicação entre as diferentes especialidades odontológicas. O fluxo de trabalho misto pode progressivamente levar a um fluxo de trabalho exclusivamente digital à medida que as tecnologias se tornem acessíveis e a curva de aprendizado superada.

Termos de indexação: Desenho assistido por computador. Prostodontia. Tecnologia odontológica. Fluxo de trabalho.

\section{INTRODUCTION}

Oral facial appearance, along to psychosocial impact, have been considered keys for oral health related to quality of life [1]. Highly esthetic treatments have driven the high demand for cosmetic dentistry worldwide [2]. To face this increasing demand, clinicians must execute a comprehensive facial and dental assessment using objective and standardized parameters to address the patient's complaints [2]. In this regard, the increasing interest in esthetic procedures has encouraged the development of new technologies, better materials, and more sophisticated dental techniques $[3,4]$ aimed at highly esthetic treatment outcomes and integration of dental specialties [1]. Such integration allows digital technologies to esthetically / functionally plan and execute.

Among digital Technologies are Computer-Aided Design/Computed-Assisted Manufacturing (CAD-CAM) systems, which have been combined with intraoral scanners to enable clinicians to take intraoral digital impressions (CAI), create a digital model, as well as design and mill the final restoration [5]. Some advantages of these systems include better dimensional accuracy and reproducibility as compared to impression materials, reduced processing time, the possibility of using new and more resistant ceramic systems, and the preparation of all-ceramic restorations [5-7]. Additionally, this technology allows the creation of a virtual treatment planning, such as the Digital Smile Design (DSD), thereby enabling different restorative or prosthetic approaches [3]. It helps strengthening diagnostic procedures, enhancing treatment predictability, and improving communication with the patient and technicians, since the system facilitates the visualization and approval of the rehabilitation planning prior to tooth preparation [3]. Furthermore, it eliminates some laboratory steps and results in better cost-effectiveness by saving chair-time [7].
While technological resources have increased patient motivation and confidence in the dental care team [3], there are some limitations to consider. First, the technology is not widespread to, and affordable by, the majority of the population [8]. Second, it demands a learning curve to all dental professionals involved, such as dentists and technicians [9]. Third, experienced dental professionals are more resistant to radical changes. It is also worth mentioning that it does not replace conventional techniques and scientific knowledge, but rather complements them [10].

In cases where esthetic and function are impaired, a multidisciplinary oral rehabilitation protocol following digital workflow can be proposed, so that to support the clinical demand for a treatment with increased predictability and shorter clinical time $[8,10]$. However, in daily practice, complete digital workflow can be difficult to be incorporated at once due to the aforementioned limitations. Nevertheless, easy-access and low-cost digital tools and devices may boost clinicians to transition to digital workflows. Hence, they may be progressively incorporated into clinical practice as they become available in order to improve treatment outcomes.

The aim of the present report was to describe the association between digital open-source software programs and low-cost devices with conventional procedures mixing conventional and digital workflow applied to a multidisciplinary oral rehabilitation, highlighting the transitional difficulties to merge from conventional to digital dentistry and the synergism between them for a better outcome

\section{CASE REPORT}

A 46-year-old female patient was referred to the university dental clinics in 2016 complaining of absence of posterior teeth and disproportionality of color, width, 
and height of the maxillary teeth. Clinical and radiographic examinations revealed the presence of chronic periodontitis (Stage II) with moderate bone destruction (Grade B) and maxillary Kennedy class III modification 1 edentulism with opposing mandibular Kennedy III. Clinical examination also showed uneven gingival contour and deficient interdental papillae as well as discrepancies in the mesiodistal width of the maxillary central incisors and marginal excess of filling material and color alteration in the right maxillary central incisor. Loss of support tissue (bone and keratinized mucosa) in the posterior edentulous region was further noticed, as shown in figures $1 \mathrm{~A}, 1 \mathrm{~B}$, and $1 \mathrm{C}$. Lastly, radiographic examination indicated satisfactory endodontic treatment of the maxillary right central incisor.

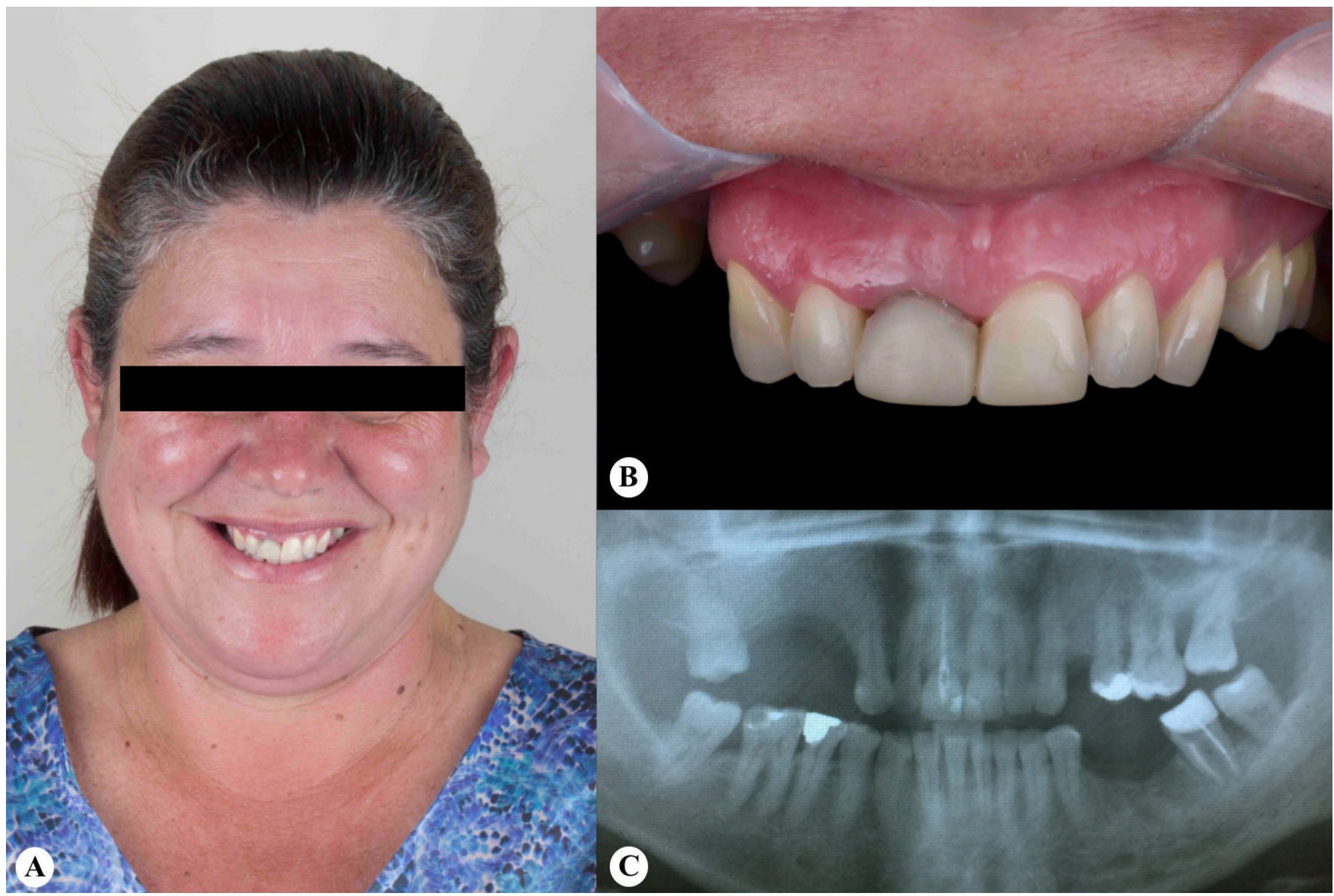

Figure 1. Initial examination of the patient; (A) Facial features; (B) View of the upper dental arch; (C) Radiographic condition.

The patient was photographed for the digital smile planning [3], and digital measurements and proportions were obtained using the Microsoft Office PowerPoint version 2010 (Microsoft, Redmont, WA, USA) (figure 2A). The DSD highlighted: 1) the differences between tooth 11 gingival contour and other teeth (pink esthetics); 2) discrepancies between diameter and length among anterior superior teeth, and between dental and facial midline; 3) the ideal position of implant placement, considering soft tissue, emergency prosthetic profile, and functional occlusion
[3]. The DSD planning was presented to the patient for approval of the clinical protocol, which consisted of $(A)$ treatment of chronic periodontitis and adequacy of the oral environment; (B) gingivoplasty surgery of the maxillary right central incisors; (C) fiberglass post treatment in the maxillary right central incisor; (D) in-office tooth bleaching; (E) use of a bioresorbable collagen membrane and a synthetic nanostructured graft material as a bone substitute (Nanosynt, FGM, Joinville, SC, Brazil) combined with osseointegrated dental implants (Straumann Dental 
Implant System, Waldenberg, Switzerland) for the posterior edentulous regions; and (F) individual lithium disilicate (IPS e.max CAD, IvoclarVivadent, Amherst, NY) crowns for the central maxillary incisors, laminate veneers for the maxillary lateral incisors and metal ceramics crowns for the implants. The patient chose not to rehabilitate the mandible arch at the moment and signed an informed consent form authorizing the treatment and documentation of the case.

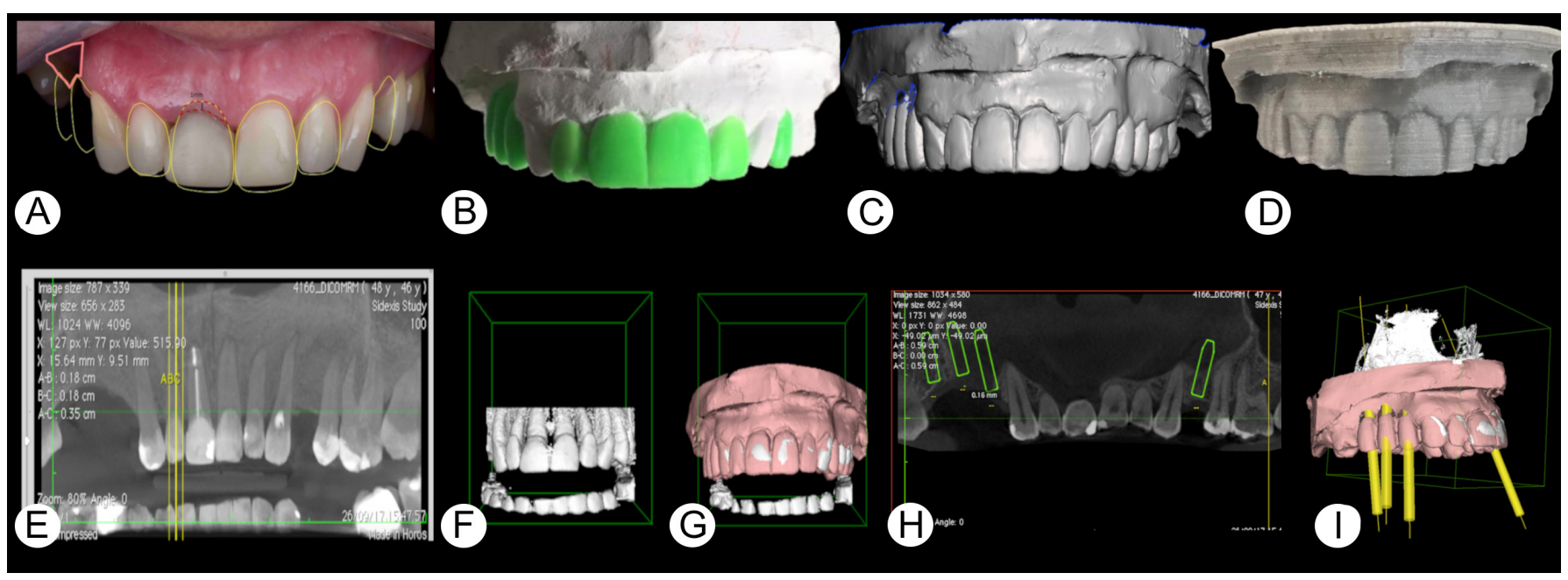

Figure 2. Digital and conventional planning; (A) Digital smile planning on Power Point; (B) Conventional wax-up based on the DSD; (C) STL file of the 3D project; (D) 3D Printed model; (E) Panoramic view of the DICOM (CBCT) file on Horos Software; (F) 3D visualization of the DICOM file; (G) Superimposition of the DICOM and STL (3D) files for implant position planning; (H) Implant planning; (I) Position of the implants based on the 3D view of the CBTC and 3D model.

Subgingival scaling and root planning were performed with the aid of periodontal curettes, and the patient received oral hygiene instructions during all clinical appointments. After adequacy of the oral environment, the patient's casts were mounted on a semi-adjustable articulator. Conventional wax-up was performed based on the 2D DSD information [3] (figure 2B) and complemented by the anterior guidance references registered by the articulator. It was then translated into a 3D project through extraoral scanning (Compact line Milling Unit M1, Zirkonzahn, Bruneck, Italy), thereby creating an STL file (figure 2C). This file was printed in polylactic acid (PLA) using the fused deposition modeling printer i3 MK3 (Prusa, Prague, Czech Republic) (figure 2D).

For dental implant planning, Cone Beam Computer Tomography (CBCT) scanning of the maxillae was performed, thereby creating a DICOM file. The DICOM and STL (3D) files were imported into the Horos software (The Horos Project) with the 3D dental plugin and superimposed (figures $2 \mathrm{E}, 2 \mathrm{~F}$, and $2 \mathrm{G}$ ). The resulted file (figures $2 \mathrm{H}$ and $2 \mathrm{I}$ ) allowed digital implant placement planning not only considering optimal bone position (DICOM) and similar emergence prosthetic profile to the
DSD (STL), but also ideal implant length / diameter and secure distances (among adjacent implants, between implants and adjacent teeth, and between implants and maxillary sinus). Since DICOM scale to real dimensions is $1: 1$, it provides reliability to measurement tools and accurate transference to conventional surgery. Thus, the ideal implant sites and the angulations provided by the software and digitally determined were transferred to a conventional cast model with the aid of calipers, rulers, and pencil marks. Over this cast model was manufactured a conventional acrylic surgical template. The guide was used to perform the surgery.

Based in the digital data provided by the surgical planning performed, four implants (Straumann Bone Level, NC Loxim with a diameter of $3.3 \mathrm{~mm}$ and SLActive Roxolid of $10-\mathrm{mm}$ and $12-\mathrm{mm}$ length) were selected and placed in the maxillary posterior region (figures $4 \mathrm{C}$ and $4 \mathrm{D}$ ) under local anesthesia and total flap surgery. The implants in the maxillary right posterior edentulous ridge were combined with biphasic hydroxide apatite graft material as a bone substitute (Nanosynt, FGM, Joinville, SC, Brazil) on the buccal wall in order to increase thickness (figure 4B). 


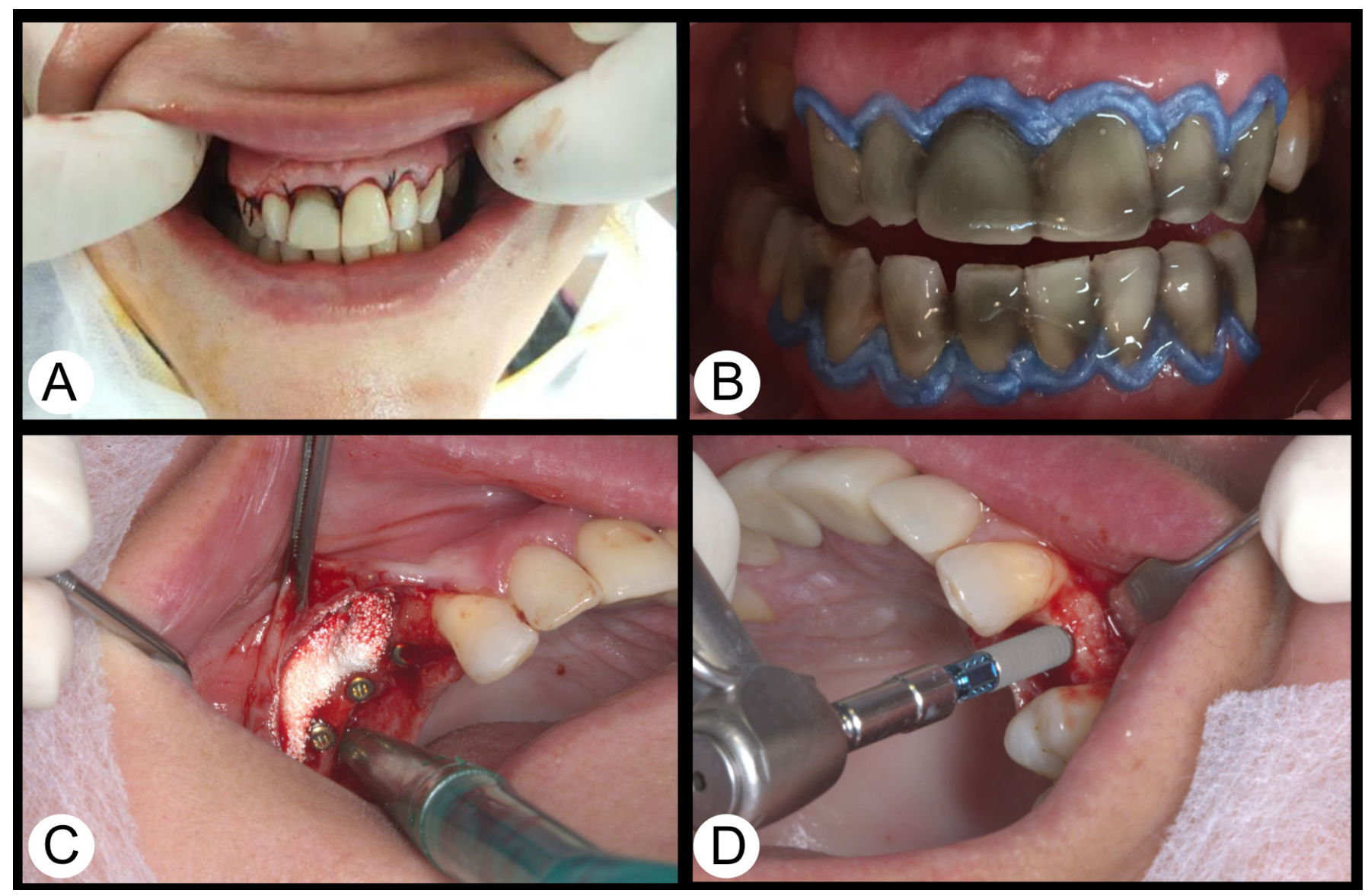

Figure 3. (A) Reverse-bevel gingivectomy procedure; (B) In-office tooth bleaching; (C) Implants placement in the maxillary right posterior ridge combined with biphasic hydroxide apatite graft material; (D) Implant placement in the maxillary left posterior ridge.

The DSD images indicated 1-mm gingival curve discrepancy in the right maxillary incisor (figure 2A). To correct the gingival architecture, the reference was transferred with the aid of a digital rule and a caliper and the excess of gingival tissue was excised through a reverse-bevel gingivectomy procedure combined with osteotomy and secured with sling sutures (figure 3A). After the healing period, the composite filling of the maxillary right central incisor was removed and the tooth was prepared and restored with a self-adhesive luting (U200, 3M ESPE, St. Paul, MN, USA) parallel-sided glass-fiber post (\#2, White Post DC, FGM, Joinville, SC, Brazil). In order to enhance the final esthetic aspect, in-office tooth bleaching was performed (35\% hydrogen peroxide, Whiteness HP Maxx, FGM, Joinville, Brazil) following the manufacturer's protocol in a single clinical session (three applications of 15 minutes each) (figure 3B).

After gingival architecture correction, DSD 3D was performed and a new model printed. Over this model, polyvinyl siloxane (Adsil, Vigodent S/A Indústria e Comércio, Rio de Janeiro, RJ, Brazil) mockups and preparation guides were obtained to guide the prosthetic rehabilitation. The mockup was tried in over unprepared teeth using bisacrylic resin (Structur, VOCO GmbH, Cuxhave, Germany) to explore teeth preparation and final prosthesis (Figure 4A). In this sense, preparation depth should be minimal in order to comply with the restorative material optimal properties performance [11]. However, increased preparation depth had to be considered in our case because of the darkened substrate of the maxillary right central incisor (figure 4A). Therefore, after esthetics approval by the patient and dental team, the maxillary lateral incisors were prepared for dental laminates, while the maxillary central incisors were prepared for metal-free crowns in order to mask the darkened dental substrate (figure 4B). Prep guides were superimposed on the prepared teeth to assure the thickness aimed: $2 \mathrm{~mm}$ buccally and incisally for the crowns, and $1 \mathrm{~mm}$ buccally and incisally for the laminates 
(figure 4C). After dental preparation, a gingival cord (Ultrapack 00, Ultradent, South Jordan, UT, USA) soaked in hemostatic agent (Hemostanc, Biodinâmica, Ibiporã, PR, Brazil) was gently pressed into de the gingival sulcus for gingival retraction. Data wa captured by an intraoral scanner (Bluecam, Dentsply Sirona, York, USA), thereby creating a new STL file. The software itself selected the color A1. Bys-acrilic (Structur, VOCO GmbH, Cuxhaven, Germany) provisional restorations remained in place for one week (figure 4D).

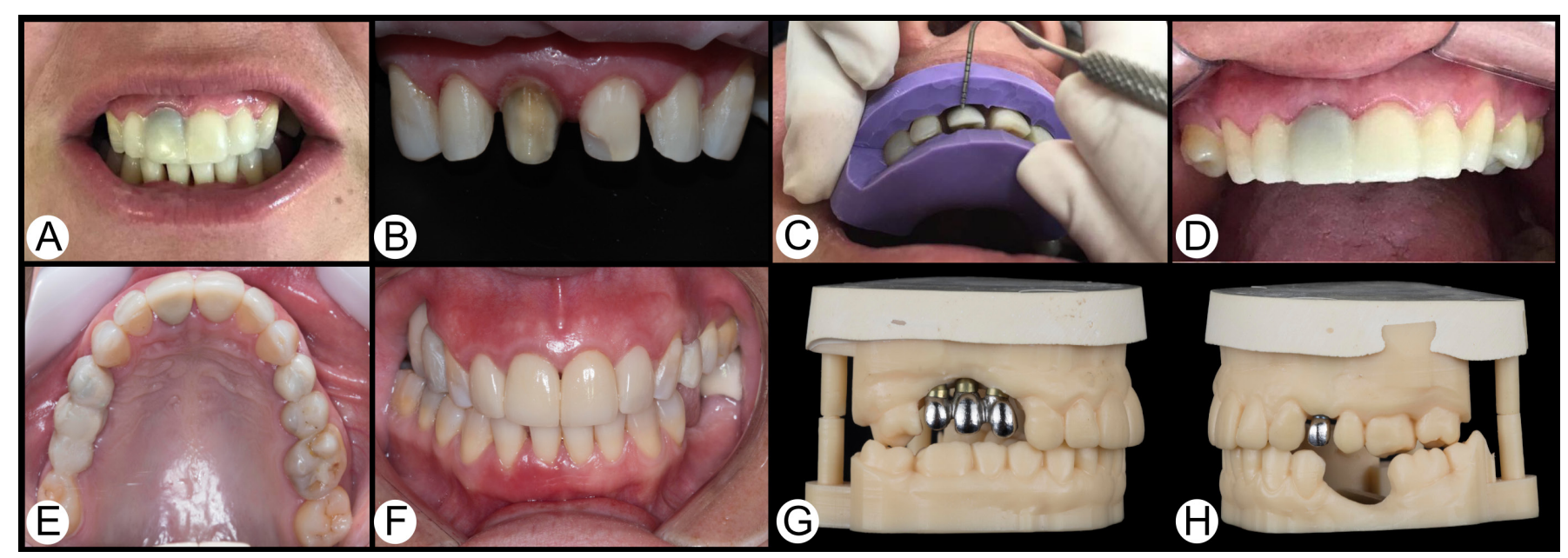

Figure 4. Prosthodontics workflow; (A) mock up restorations tried in over unprepared teeth; (B) Anterior view of the crowns preparation; (C) Prep guides superimposed on the prepared teeth to assure the thickness aimed; (D) Mock up restorations over prepared teeth; (E and F) Provisional crowns; (G and H) Printed model with the metallic portion of the metal-ceramic crowns.

Subsequently, the prepared teeth scan file and the DSD file were merged to enable the replication of the DSD to design and mill the definitive restoration. Monolithic lithium disilicate (IPS e. max CAD, IvoclarVivadent, Schaan, Liechtenstein) laminates were selected for the for the maxillary lateral incisors, while the maxillary central incisors received yttria-stabilized tetragonal zirconia (Y-TZP, Zirkonzahn GmbH, Bruneck, Italy) crowns due to the better optical properties of the Y-TZP (higher opacity and less translucency) as compared to vitreous and lithium disilicate ceramics [12]. The milled pieces received external characterization through colorants and glaze. Previously to the luting procedure, the restorations were tried in with the use of the tooth-colored glycerine gel (Try-in, Variolink N, IvoclarVivadent, Schaan, Liechtenstein) to assess their shape and shade. We selected a light / dual cure resin cement (A1, Variolink N, IvoclarVivadent, Schaan, Liechtenstein) to lute the laminated and the crowns, respectively. Luting procedures were performed following the manufacturers' instructions.
After six weeks the implants' surgical places were reassessed following the same protocol for the initial placement. It was observed the level and curvature of the bone augmentation obtained and color / texture of the marginal peri implant soft tissue. We opted to not use healing abutments in order to preserve soft tissue thickness. Instead, we performed the installation of characterized provisional acrylic crowns on stock temporary abutments (NC, Straumann, Waldenberg, Switzerland) (figure 4E and 4F). The Provisional crowns were obtained duplicating the 3D printed model. Thereafter, the selection of implant definitive abutments was performed through a new oral scanning (3Shape, TRIOS, Copenhagen, Denmark) using scan bodies (Mono, CARES Narrow Crossfit - Neodent Straumann, Curitiba, Brazil) compatible with the implants. The model was printed with the abutment analogues. NC Screw-retained Abutments (TAN, $4.6 \mathrm{~mm}$ of diameter and $2.5 \mathrm{~mm}$ ) were selected and metal-ceramic crowns were produced (Figure $4 \mathrm{G}$ and $4 \mathrm{H}$ ). The crowns were then tested and installed accordingly (figures 5A, 5B, and 5C). Patient was inquired about comfort and esthetics satisfaction and received hygiene and care orientations. 


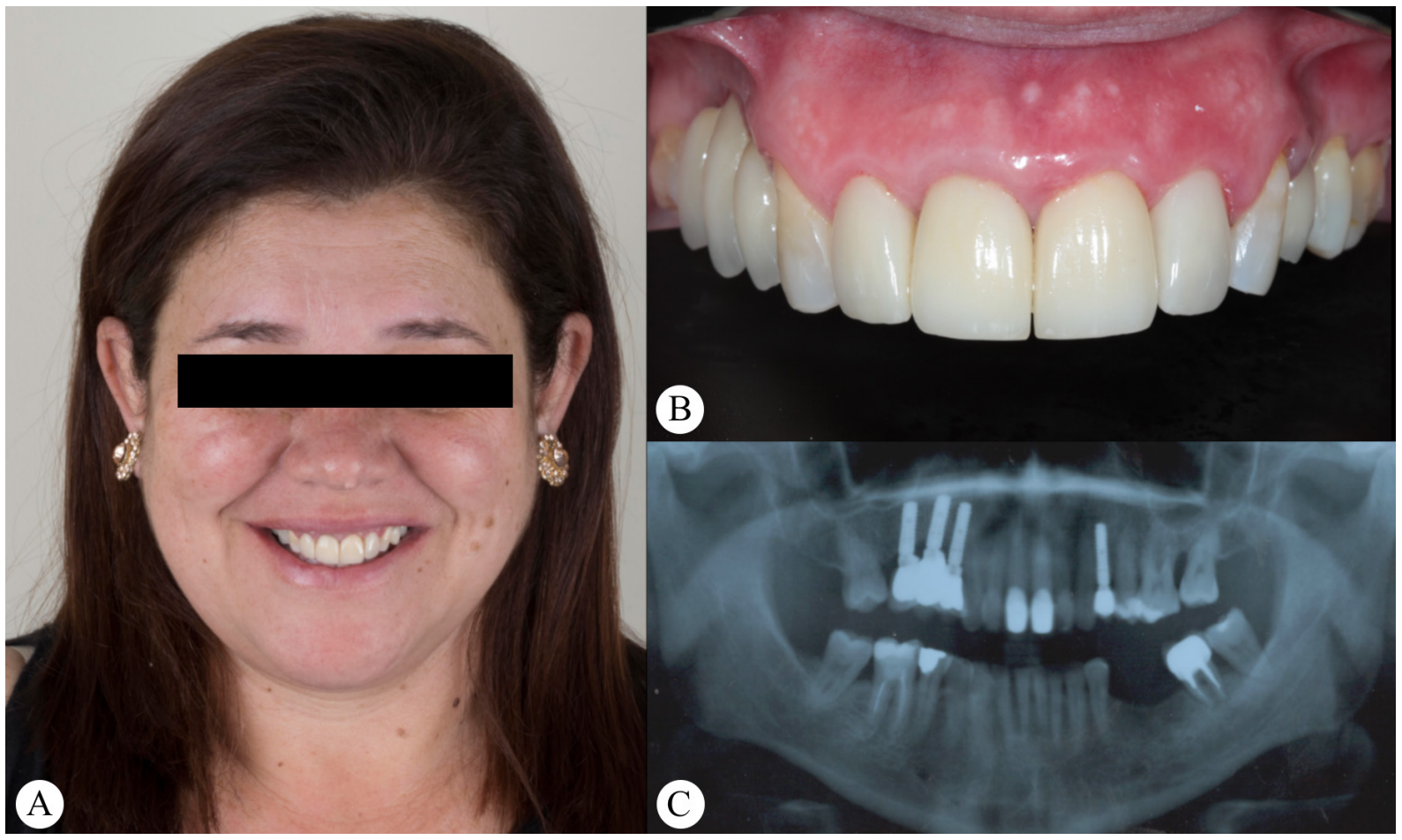

Figure 5. Patient's clinical outcomes. (A) Post-treatment facial features; (B) Final view of the upper dental arch; (C) Final radiographic condition.

In the 18 months follow up, occlusion, periodontal and 9D). No complications were detected and the patient tissue, and prostheses were checked (figures 6A, 6B, 6C, related satisfaction and comfort.

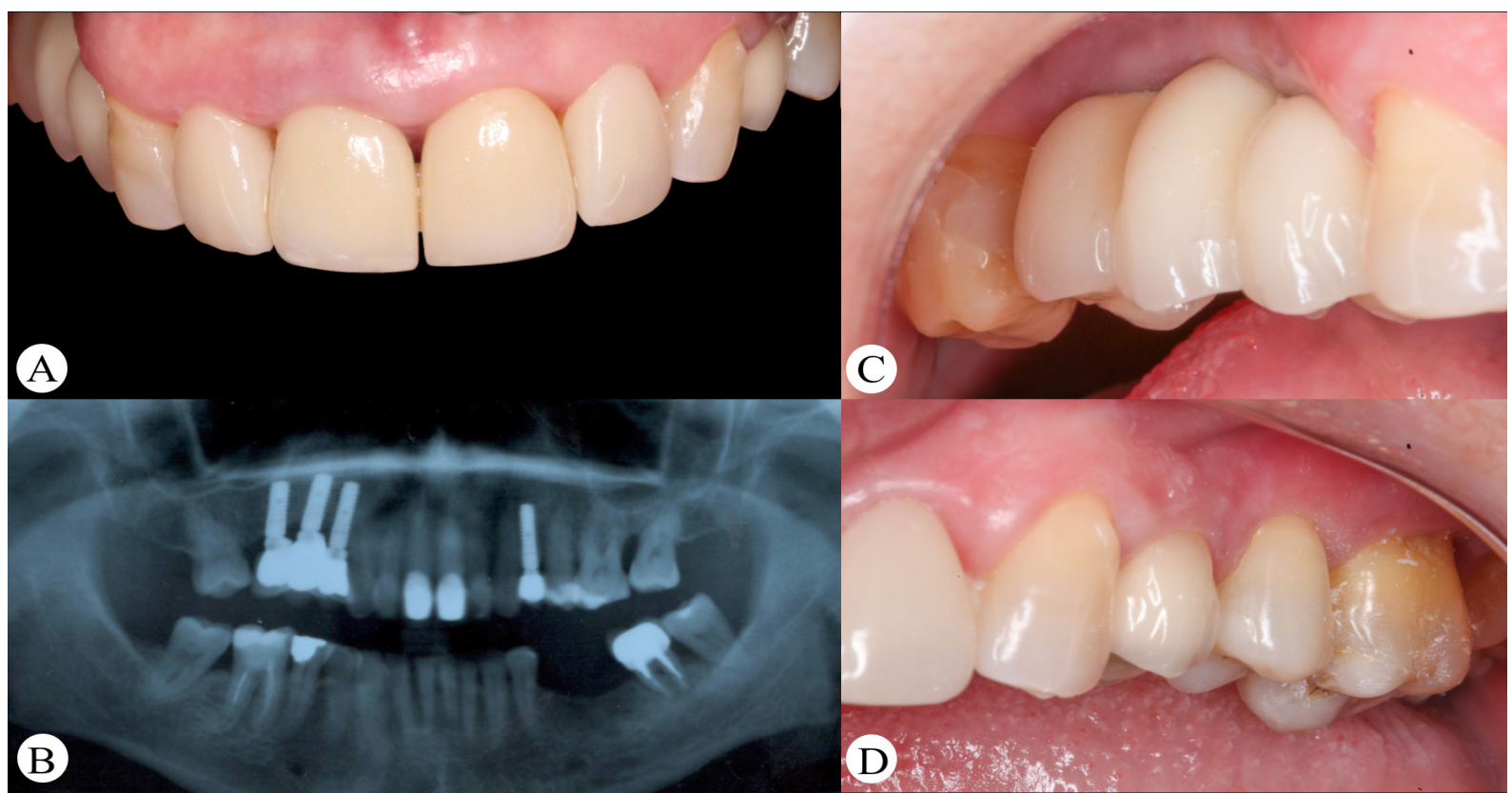

Figure 6. Patient's clinical outcomes after 18 months. (A) View of the upper dental arch; (B) Radiographic condition; (C) Lateral right view of the upper dental arch; (D) Lateral left view of the upper dental arch. 


\section{DISCUSSION}

The present clinical report describes the use of digital and conventional methods for a mixed workflow in a multidisciplinary oral rehabilitation of a partially edentulous patient, aiming at helping clinicians to begin the transition from analog to digital dentistry. Digital dentistry is a ubiquitous phenomenon nowadays. The use of intraoral and facial scanners, CBCT, CAD/CAM, guided surgeries, 3D printers, milling machines, and new esthetic materials, has been substantially transforming conventional dental care. Nevertheless, technological advances have also posed a challenge for dental professionals, since there is a constant need for learning how to operate new devices, software, and machines as well as how to integrate them into daily practice [13].

The digital workflow was shown to be more efficient in terms of working time and cost-effectiveness than conventional techniques. Mühlemann et al. [14] evaluated the conventional and digital workflows and showed that dental teams spend significantly less time with the digital approach, regardless of the CAD-CAM system used, which is consistent with the findings of Sailer et al. [15]. Furthermore, Joda \& Brägger [16] demonstrated that the digital implant-prosthetic workflow costs $18 \%$ less as compared to the conventional approach. Despite that, dentists seem to believe that the digital workflow is not costeffective [17]. The laboratorial and clinical costs involved are commonly reduced in the digital workflow, which leads to a potential increase in the dentist's productivity and profit. In the present case, however, the overall cost was not reduced. It is possible that cost reduction may occur progressively as conventional / mixed workflows turn into complete digital approaches and technologies become more accessible to dental teams. While the digital workflow remains an important advance in dentistry, enabling a more efficient and streamlined treatment, it is not routinely accessible to clinicians. We did not experience an easy access to the tools and components used in the CAI/CAD/CAM protocol, although the literature shows a tendency to greater diffusion of the digital workflow among clinicians in the near future [17].

On the contrary of the aforementioned CAI/CAD/ CAM limitations, we highlight the easy use of accessible software programs such as PowerPoint (Microsoft) and Horos (The Horos Project), an open-access (free) software, as well as a low-cost printer (Prusa i3). It considerably reduced the cost of the rehabilitation which could enable clinicians to replicate the protocol. The use of different tools for digital smile planning has been recently revised, and should include facial, dentogingival, and dental esthetic parameters [2]. PowerPoint contemplates all of them. Likewise, Horos Software (The Horos project) is focused on DICOM files reading, but it allows adds on, such as 3D dental plugin, and the use of different files formats obtained from different devices. It benefits reverse implant planning in open-source and free-of-charge software. Closed-systems offer more coherence in data processing during all stages, but presents limited access [7]. Therefore, the application of different more accessible software programs and devices in the present protocol is innovative and may encourage clinicians to incorporate digital dentistry in daily practice.

Digital technologies allow the creation of a synergistic dental workflow among the different dental specialties, resulting in improved treatment outcomes. The case presented herein reports an association of conventional and digital procedures for periodontal, restorative, implant, and prosthetic treatments. This case reinforces the importance of multidisciplinary dental care across different fields for the success of the treatment plan. In fact, the use of CAI/CAD/CAM integrating the different interdependent phases and dental specialties has shown to decrease error margins and to increase quality control of the treatment [18]. In addition to an integrated planning, better outcomes with digital dentistry can be related to special image process algorithms, which provides an excellent image quality and consequently higher accuracy, resulting in positive outcomes, such as better marginal fit of ceramic crowns [19].

Nevertheless, further studies are needed to guarantee the efficiency of digital technologies. Recent meta-analysis pointed the low-quality evidence for digital impressions, compared to conventional techniques [20]. For instance, an important shortcoming is the fact that subgingival preps have been related to a limitation of optical impression systems [21]. In the present case we used retraction cord and astringent liquid to promote a clear view and access to the optical system, which resulted in a clinically acceptable digital impression. This technique highlights the association of conventional and digital steps aiming at providing the patient with the best treatment that we had access. Regardless of limitations, several advantages support digital techniques, such as easy 
storage / replication and possibility of immediate evaluation of the data acquired, which allows prompt adjustments [20]. These assumptions should encourage the transition to digital dentistry as technologies and devices become available and more evidences are provided.

Importantly, the digital workflow alone does not guarantee success of the clinical rehabilitation. When surveying the opinion of dentists on the use of digital technologies, Van derZande et al. [17] demonstrated that the degree to which a technology is thought to be "effortless" is directly related to its implementation in dental practice. Additionally, the assumption that technology pushes dentists away from the core of the profession and imposes too many procedures was also significant. Therefore, it is critical to highlight the inaccurate view of dentists regarding technological innovation. In fact, digital dentistry has been introduced with the purpose of reducing the working time and enhancing productivity and communication among the dental team [19] and not to exempt dentists from treatment-related assignments. For instance, while digital tools provide a guide to minimal dental preparations, they do require the operator's knowledge about the physical and mechanical properties of dental materials and substrates for the success of the case. It is noticeable in our case due to the fact that lithium disilicate was initially selected for milling all restorations due to its low refractive index and great translucency, despite its high crystalline content. However, even using a low translucency and opaque try-in cement, a grayish halo could be still seen at the maxillary right central incisor cervical region, which led us to select yttria-stabilized tetragonal zirconia for the central incisors. Thus, the introduction of technologies into practice is not expected to supplant the dentist's role, but rather to assist in dental care.

As far as the success of implant-prosthetic treatment is concerned, the use of tools that provide better accuracy and outcomes should be considered. Besides guiding the correct architecture of gingival curve and peri-implant soft tissues in esthetic sites based on the patient's dentition and facial frame [22], the use of technology allows for a precise and reproducible assessment of implant-prosthetic parameters. The use of CBCT combined with intraoral scanning enables a preoperative planning of the implant position based on anatomical boundaries, such as the volume of peri-implant bone tissue and the requirement for esthetic [22], while eliminating conventional preoperative impression. Unfortunately, a limitation of our report is the fact that we had no access to a digital surgical guide, which could have improved the results and guided the surgical procedure, resulting in better outcomes. However, the use of dataset superimposition for implant sites planning successfully helped surgical planning and reduced surgical time. Additionally, because we aimed at introducing easyaccess tools that could help clinicians begin the transition to digital dentistry, the possibility of transferring the software measurements and planning to conventional casts and surgery is within our scope. As technologies continue to advance in dental offices, more digital steps can be executed progressively, such as digital guided surgeries. In this sense, digital revolution is spreading exponentially, but digital workflows can be incorporated according to clinicians' individual characteristics and accessibility.

Nonetheless, the incorporation of digital workflows into daily practice has been limited. While research on "digital dentistry" has more than doubled over the last ten years, the out-most number of publications on this topic has addressed single-unit restorations and shortspan fixed dentures [10]. The present clinical case provides important evidence on the usefulness of digital workflow for multidisciplinary oral rehabilitation with 18 months of follow up. It is worth mentioning that scientific evidence for clinical feasibility of the digital workflow is essential to understand the impact of the digital dentistry on modifying well-established traditional protocols. The present study highlights the utilization of mixed treatment protocols combining conventional and digital steps. The digital systems are constantly improving; hence the clinical report described herein is limited to the technology available at the time when the case was performed and emphasize the importance to keep up-to-date with the new virtual technologies in order to offer the best possible treatment, centered in accuracy and predictability [23]. Furthermore, in this case we did not rehabilitate the edentulous area in the mandibular arch of the patient as per her personal choice. Longitudinal clinical trials should be carried out to investigate the benefits of digital technologies as compared to conventional approaches and the long-term effectiveness of this novel rehabilitation design.

\section{CONCLUSION}

Multidisciplinary treatment approach is one of the most challenging conditions in oral rehabilitation. The association between conventional and digital workflows 
enhanced predictability and facilitated the communication among the different dental specialties in our case report. Rehabilitative and cosmetic dentistry are on permanent progress and digital technology is in constant evolution, although its access is still limited due to cost and experience curve. Nevertheless, the use of open-source and low-cost digital tools and devices used improved diagnosis, treatment plan and were adjuvants to conventional techniques, benefiting our outcomes. In this sense, different digital tools and devices may be incorporated in multidisciplinary oral rehabilitations and progressively replace the conventional workflow as they become more accessible to clinicians.

\section{Collaborators}

A ZAVOLSK and F GRANVILLE, performed the clinical steps. MC POMINI wroted and edited manuscript. FB OLIVEIRA and $L O B$ PINHEIRO co-wroted and corrected the overall manuscript. P RUNNACLES reviewed the overall manuscript. APB SAMRA coordinated the case, performed the clinical steps, cowrote and corrected the manuscript.

\section{REFERENCES}

1. Larsson $P$, Bondemark L, Häggman-Henrikson B. The impact of orofacial appearance on oral health related quality of life: a systematic review. J Oral Rehabil. 2020. http://dx.doi. org/10.1111/joor.12965

2. Omar D, Duarte C. The application of parameters for comprehensive smile esthetics by digital smile design programs: a review of literature. Saudi Dent J. 2018;30(1):712. http://dx.doi.org/10.1016/j.sdentj.2017.09.001

3. Coachman C, Calamita M. Digital smile design: a tool for treatment planning and communication in esthetic dentistry. Quintessence Dent Technol. 2012;35:103-111.

4. Soares PV, Spini PH, Carvalho VF, Souza PG, Gonzaga RC, Tolentino $A B$, et al. Esthetic rehabilitation with laminated ceramic veneers reinforced by lithium disilicate. Quintessence Int. 2014;45(2):129-133. http://dx.doi.org/10.3290/j.qi.a31009

5. Arcuri L, Lorenzi C, Cecchetti F, Germano F, Spuntarelli M, Barlatanni A. Full digital workflow for implant-prosthetic rehabilitations: a case report. Oral Implantol. 2015;8(4):114-121. http://dx.doi.org/10.11138/orl/2015.8.4.114

6. Kusai B, Shukran NI. Assessment of chair-side computer: aided design and computer-aided manufacturing restorations: A review of the literature. J Oral Health. 2015;7(4):96-104.

7. Samra APB, Morais E, Mazur RF, Vieira SR, Rached RN. CAD/CAM in dentistry: A critical review. Rev Odonto Cienc. 2016;31(3):140144. http://dx.doi.org/10.15448/1980-6523.2016.3.21002
8. Arias DM, Trushkowsky RD, Brea LM, David SB. Treatment of the patient with gummy smile in conjunction with digital smile approach. Dent Clin North Am. 2015;59(3):703-16. http://dx.doi.org/10.1016/j.cden.2015.03.007

9. Cheng CW, Ye SY, Chien CH, Chen CJ, Papaspyridakos P, Ko CC. Randomized clinical trial of a conventional and a digital workflow for the fabrication of interim crowns: An evaluation of treatment efficiency, fit, and the effect of clinician experience. J Prosthet Dent. 2021;125(1):73-81. http://dx.doi. org/10.1016/j.prosdent.2019.08.006

10. Joda T, Zarone F, Ferrari M. The complete digital workflow in fixed prosthodontics: a systematic review. BMC Oral Health. 2017;17(1):124. http://dx.doi.org/10.1186/s12903-017-0415-0

11. Pires LA, Novais PM, Araújo VD, Pegoraro LF. Effects of the type and thickness of ceramic, substrate, and cement on the optical color of a lithium disilicate ceramic. J Prosthet Dent. 2017;117(1):144-149.

12. Kelly JR, Benetti P. Ceramic materials in dentistry: historical evolution and current practice. Australian Dent J. 2011;56(1):8496. http://dx.doi.org/10.1111/j.1834-7819.2010.01299.x

13. Mangano F. Digital dentistry: The revolution has Begun. Open Dent J. 2018;12:59-60. http://dx.doi.org/10.2174/18742106 01812010059

14. Mühlemann S, Benic GI, Fehmer V, Hammerle CHF, Sailer I. Randomized controlled clinical trial of digital and conventional workflows for the fabrication of zirconia-ceramic posterior fixed partial dentures. Part II: Time efficiency of CAD-CAM versus convention all laboratory procedures. J Prosthet Dent. 2018;121(2):252-257. http://dx.doi.org/10.1016/j. prosdent.2018.04.020

15. Sailer I, Benic GI, Fehmer V, Hammerle CHF, Muhlemann S. Randomized controlled with in-subject evaluation of digital and conventional workflows for the fabrication of lithium disilicate single crowns. Part II: CAD-CAM versus conventional laboratory procedures. J Prosthet Dent 2017;118(1):43-48. http://dx.doi.org/10.1016/j.prosdent.2016.09.031

16. Joda T, Brägger U. Digital vs. conventional implant prosthetic workflows: a cost/time analysis. Clin Oral Implants Res. 2015;26(12):1430-1435. http://dx.doi.org/10.1111/clr.12476

17. Van der Zande MM, Gorter RC, Bruers JJ, Aartman $I H$, Wismeijer D. Dentists' opinions on using digital technologies in dental practice. Community Dent Oral Epidemiol. 2018;46(2):143-153. http://dx.doi.org/10.1111/cdoe.12345

18. Weston J. Closing the gap between esthetics and digital dentistry. Compend Contin Educ Dent. 2016;37(2):84-91.

19. Stanley M, Paz AG, Miguel I, Coachman C. Fully digital workflow, integrating dental scan, smile design and CADCAM: case report. BMC Oral Health. 2018;18(1):134. http:// dx.doi.org/10.1186/s12903-018-0597-0

20. Borbely J. Low-quality Evidence Suggests Digital Impressions (DIs) and conventional impressions are comparable for marginal and internal fit, very-low quality evidence for interproximal and occlusal contacts is insufficient to draw conclusion and there is no evidence regarding survival of full-coverage restorations. J Evid Based Dent Pract. 2019;19(4):101347. http://dx.doi.org/10.1016/j.jebdp.2019.101347 
21. Nedelcu R, Olsson P, Nyström I, Thor A. Finish line distinctness and accuracy in 7 intraoral scanners versus conventional impression: an in vitro descriptive comparison. BMC Oral Health. 2018;18(1):27. http://dx.doi.org/10.1186/s12903-0180489-3

22. Benic Gl, Elmasry M, Hämmerle $\mathrm{CH}$. Novel digital imaging techniques to assess the outcome in oral rehabilitation with dental implants: a narrative review. Clin Oral Implants Res. 2015;26(11):86-96. http://dx.doi.org/10.1111/clr.12616
23. Edelhoff D, Probst F, Ehrenfeld M, Prandtner O, Schweiger J, Liebermann A. Interdisciplinary full-mouth rehabilitation for redefining esthetics, function, and orofacial harmony. J Esthet Restor Dent. 2019;31(3):179-189. http://dx.doi.org/10.1111/ jerd.12455. doi:10.1111/jerd.12455

Received on: 9/4/2020

Final version resubmitted on: 4/6/2020

Approved on: 8/6/2020 